\title{
Occupational exposures and chronic obstructive pulmonary disease: a hospital based case-control study
}

\author{
Nadira Govender, ${ }^{1}$ Umesh G Lalloo, ${ }^{2}$ Rajen N Naidoo ${ }^{1}$
}

${ }^{1}$ Department of Occupational and Environmental Health, University of KwaZulu-Natal, Durban, South Africa ${ }^{2}$ Department of Pulmonology and Critical Care Medicine, University of KwaZulu-Natal, Durban, South Africa

\section{Correspondence to} Professor Rajen Naidoo, Department of Occupational and Environmental Health, George Campbell Building, University of KwaZulu-Natal, Durban 4041, South Africa;

naidoon@ukzn.ac.za

Received 20 August 2010 Accepted 17 March 2011 Published Online First 17 April 2011
ABSTRACT

Background 0ccupational exposures are associated with chronic obstructive pulmonary disease (COPD). This study investigated this association among a population with a high prevalence of tuberculosis and smoking. Methods Cases $(n=110)$ diagnosed by pulmonologists were selected from specialist respiratory clinics. Frequency sex- and age-matched controls $(n=102)$ were selected from other clinics at the same institutions. Lifetime occupational exposure histories were obtained through interviews. Exposure variables derived from the ALOHA Job Exposure Matrix (JEM) were used to complement the self-reporting variables. ORs were calculated from logistic regression models, adjusting for smoking and past history of tuberculosis. Percentage population attributable risk (PAR\%) was also calculated. Results The adjusted ORs for COPD from the JEMderived high cumulative biological dust exposure, high cumulative mineral dust exposure and high cumulative gas and fumes exposure were 2.1 (95\% Cl 1.1 to 4.2$)$, 1.1 (95\% Cl 0.6 to 2.4 ) and 1.8 (95\% Cl 0.8 to 3.9$)$, respectively. Self-reported occupational exposures were associated with higher risks, with adjusted ORs for high dust exposure-years and high chemical, gas and fumes exposure-years of 5.9 (95\% Cl 2.6 to 13.2) and 3.6 (95\% Cl 1.6 to 7.9), respectively. Among ever smokers, there was an increased risk for COPD, with ORs ranging from 5.0 to 5.5. Tuberculosis was a strong risk factor, with an OR ranging from 7.7 to 8.1 . The PAR\% was $25 \%$ for selfreported high exposures, but lower when the JEM variables were used.

Conclusions Lifetime occupational exposures contribute to the risk of COPD, adjusted for smoking. These risks are present in populations with a high burden of tuberculosis, which is considered an important causative factor.

\section{INTRODUCTION}

Chronic obstructive pulmonary disease (COPD) is increasing worldwide, in both developed and developing countries. According to the 2001 World Bank/WHO Global Burden of Disease report, COPD is the sixth leading cause of death in developing countries, responsible for $4.9 \%$ of deaths. ${ }^{1}$ Despite smoking being the most important risk factor for this disease, accounting for $>75 \%$ of cases of disease, occupational exposures, alone or in combination with smoking, are responsible for a substantial proportion of disease. ${ }^{1-3}$ Work may have an interactive effect with tobacco smoke, resulting in greater severity of disease with greater disability or by accelerating the rate of loss of lung function among those with the disease. ${ }^{4}$

\section{Key Messages}

What is the key question?

- Are occupational exposures associated with chronic obstructive airways disease in a population with ahigh prevalence of tuberculosis?

\section{What is the bottom line?}

- Occupational exposures contribute to the risk of chronic obstructive pulmonary disease, adjusted for smoking. These risks are present in populations with a high burden of tuberculosis, which is considered an important causative factor.

\section{Why read on?}

- Although occupational exposures have been consistently documented to be associated with chronic obstructive pulmonary disease over the last several years, there is a limited understanding of these associations in countries with other important risk factors such as chronic pulmonary infections. This study investigates associations among a high tuberculosis prevalence population.

Since the seminal paper on chronic airflow limitation and occupational exposures by Margaret Becklake in 1989, the evidence for work-related COPD has grown substantially. 5 Occupational exposures such as to vapours, gases, dusts and fumes present an important risk factor for the development of the disease, by itself and through interaction with other risk factors. A US study of $>10000$ adults concluded that COPD attributable to work was $\sim 19 \%$ in the total population, and $31.1 \%$ among never smokers. ${ }^{6}$ The American Thoracic Society's consensus statement suggests that between $10 \%$ and $20 \%$ of COPD is attributable to workplace exposures. ${ }^{2}$ The epidemiological evidence supporting the role of occupational exposures (organic and inorganic dusts, metal fumes, chemical vapours) as risk factors has been published in population-based studies, ${ }^{6-8}$ and also studies regarding working environments with specific exposures. $^{9-12}$

In developing countries, in addition to smoking, COPD is associated with the high burden of infectious respiratory diseases, particularly tuberculosis (TB). ${ }^{13-15}$ The role of occupational exposures against this background of infectious diseases has not been investigated previously. This study 
was undertaken to determine whether lifetime workplace exposures are associated with COPD, after adjusting for smoking, in a hospital sample of patients with known COPD, compared with hospital-selected controls among a population with elevated prevalence of TB.

\section{METHODS}

\section{Selection of clinics and participants}

This hospital-based study was conducted at three tertiary public health hospitals in KwaZulu-Natal province of South Africa. Ethical approval was obtained from the Biomedical Research Ethics Committee of the University of KwaZulu-Natal, and participation was voluntary. The three specialist respiratory centres that exist in the province are located at these institutions. Cases of COPD were defined on the basis of a pulmonologist diagnosis. These specialists employed the Global Initiative on Obstructive Lung Disease (GOLD) definition using spirometric assessments. ${ }^{16}$ All patients, presenting for the first time or for follow-up visits to these centres over a 6-month period, and meeting this case definition, irrespective of severity, age or current employment status, were invited to participate. Controls were drawn from clinics other than those for respiratory chronic diseases (the cardiovascular, renal and diabetes clinics) at the same institutions, selected over the same time period as the cases. Potential controls were excluded if they reported ever having had a diagnosis of COPD, asthma, chronic bronchitis or emphysema, or if they had used any COPD medication including inhalers within the past 12 months. No one was excluded on the basis of having had TB previously. This information was extracted from their hospital records, through consultation with the attending physician, and verified during the interview process. No chest radiographs or spirometry data were available for the controls. Controls and cases were group frequency matched for sex and age, within 5 years. One-to-one matching was not done. We were not able to obtain an equal number of control for all the cases that we had, despite several attempts. Participants were either English or isiZulu speakers.

\section{Participant interviews}

All participants were interviewed using instruments which had been translated into isiZulu, back-translated into English and extensively field tested in South Africa. ${ }^{17}$ Interviews were conducted by trained interviewers in the language of choice (either English or isiZulu) of the participants. The questionnaire included questions on demographics, medical history, respiratory symptoms, smoking habits and family history, Another key covariate, TB, was assessed by asking 'have you ever had chest tuberculosis' (with a 'yes/no' response) and, if yes, 'was this confirmed by a doctor'.

\section{Exposure assessment}

Several questions concerning occupation were incorporated into the questionnaire, modified from the European Community Respiratory Health Survey (ECRHS) II. $^{18}$ These included: employment status, current and all previous jobs held (job description, industry, start and end date for each job), and selfreported occupational exposures for each job, up to a maximum of five. Information on all jobs held over the participant's working life (starting from current, and working towards since leaving school) was collected, up to a maximum of 10 . If the employment was in the same industry but in different occupational categories, they were treated as different jobs. These latter series of questions were open ended. In addition, a series of closed questions relating to employment in industries with exposures associated with the development of COPD, including duration of exposure, were also included. These included questions on whether or not they had ever worked in a foundry, with asbestos, in a pottery, with diesel or diesel fumes, in a flax, cotton or hemp mill, in tunnelling, in drilling, in sandblasting, in a quarry and with any other dusty occupations or with chemicals. If a positive response was received for the latter industries, then the respondent had to indicate the duration of employment in that industry. The latter closed questions were used to validate the responses for the open-ended questions. The study region in South Africa is away from the major mining centres, and hence there was minimal mining exposure in our sample.

These jobs were then coded using the four-digit code of the International Standard Classification of Occupations (ISCO-88). ${ }^{19}$ Using these codes, the ALOHA Job Exposure Matrix (JEM), previously used for COPD, ${ }^{720}$ classified participants as having exposure to biological dusts, mineral dusts, gases and fumes. The ALOHA JEM scores 0, 1 and 2 (non, low, high) were squared before multiplying by duration. By summing the JEM-derived scores for years worked in these exposures, a cumulative exposure variable for each of these three exposure categories was established.

\section{Statistical analysis}

Data were analysed using STATA version 10.

Two composite exposure variables (dust, and chemicals, gases and fumes (CGF)) and duration of exposure to each were calculated from the self-reported data. The information from the open-ended questions reported by participants during the interview was used for analysis. For the logistic regression models, the exposure variables obtained through self-reporting and the JEM were used. Using exposed controls as the reference group, three exposure categories for each of these variables were obtained: non-exposed, low exposure and high exposure, using the median exposure among exposed controls as a cut-off point. Covariates of interest for COPD that were included in our logistic regression modelling included age, sex, smoking status and reported history of previous $\mathrm{TB}$ as confirmed by a doctor. All participants in the study were drawn from public sector hospitals, and therefore belonged to a narrow socio-economic stratum. For this reason, no adjustments for socio-economic status were done in the analysis.

Three logistic regression models were run, one for each exposure variable obtained through the JEM, and a further two models for each of the self-reported exposure history (to dust and CGF) were run. Smoking variables, categorised as never and ever smoking, evaluated the effect of smoking on risk of COPD. For the multivariate logistic regression models, ORs and 95\% CIs are presented.

To determine the proportion of COPD cases attributable to occupational exposures, the percentage population attributable risk (PAR\%) was calculated, using the method described by Weinmann et al $\left(\mathrm{PAR} \%=((\mathrm{OR}-1) /(\mathrm{OR})) \times \mathrm{P}_{\mathrm{e}}\right.$ where $\mathrm{P}_{\mathrm{e}}=$ proportion of cases exposed). The ORs were those obtained from the logistic regression models. ${ }^{21}$

\section{RESULTS}

The sample comprised a total of 110 cases with a physicianconfirmed diagnosis of COPD and 102 controls (table 1). According to the GOLD classification of COPD severity, $69.4 \%$ of cases were in stages III and IV, while none was in stage I. Of those invited to participate, three (two cases and one control) 
Table 1 Demographic and smoking characteristics of cases and controls

\begin{tabular}{lcc}
\hline Characteristic & Cases $(\mathbf{n}=\mathbf{1 1 0})$ & Controls $(\mathbf{n}=\mathbf{1 0 2}$ \\
\hline Age (mean) (SD) & & \\
$\quad$ Male & $61.4(9)$ & $62.6(8)$ \\
Female & $62.5(9)$ & $58.5(11)$ \\
Sex, $\mathrm{n}(\%)$ & $96(87)$ & $91(89)$ \\
$\quad$ Male & $14(13)$ & $11(11)$ \\
$\quad$ Female & & \\
Smoking status, $\mathrm{n}(\%)$ & $8(7)$ & $27(26)$ \\
$\quad$ Non-smokers & $79(72)$ & $47(46)$ \\
$\quad$ Ex-smokers & $23(21)$ & $28(27)$ \\
$\quad$ Current smokers & & \\
TB status & $17(15)$ & $2(2)$ \\
$\quad$ History of TB & & \\
\hline
\end{tabular}

TB, tuberculosis.

refused. In both the groups, males constituted just fewer than $90 \%$ of participants. Cigarette smoking differed between cases and controls (93\% vs $74 \%$ ever smokers); however, cases were more likely to be ex-smokers. Reported history of TB was greater among cases than controls (table 1).

The 110 cases reported a total of 340 job descriptions, compared with the 221 job descriptions reported by controls. A larger proportion of the controls reported employment in administrative ( $21 \%$ vs $12 \%$ ), managerial ( $8 \%$ vs $3 \%$ ) and quality control $(5 \%$ vs $0.3 \%)$ positions compared with cases. Cases were more likely to be machinists ( $9 \%$ vs $6 \%$ ), builders ( $8 \%$ vs $3 \%$ ) and fitters and turners ( $6 \%$ vs $2 \%$ ) compared with controls (table 2).

All cases reported having at least one job over their lifetime, while among the controls $97 \%$ had at least one job over their lifetime, with 4 (4\%) listing their jobs as full-time house persons. Employment status ('ever being employed') did not differ significantly between cases and controls. However, cases were more likely to be currently unemployed due to poor health than controls $(53 \%$ vs $17 \%, \mathrm{p}<0.02)$ (table 3 ).

Occupational exposures, measured through self-reporting and JEM, were more common among the cases than controls. Selfreported exposure to dust, CGF and mixed dust-CGF exposure was significantly different between cases and controls (table 3 ).

The duration of self-reported occupational exposures differed significantly between cases and controls $(p<0.001)$. The mean number of years for exposure to dust and CGF was $\sim 3-4$ times

Table 2 Frequent job descriptions reported by cases and controls

\begin{tabular}{lcc}
\hline Job description* & $\begin{array}{l}\text { Jobs among cases } \\
\mathbf{n}(\%)(\mathbf{n}=\mathbf{3 4 0})\end{array}$ & $\begin{array}{l}\text { Jobs among controls } \\
\mathbf{n}(\%)(\mathbf{n}=\mathbf{2 2 1})\end{array}$ \\
\hline Administrative & $41(12)$ & $47(21)$ \\
Machinist (textile and shoe) & $30(9)$ & $13(6)$ \\
Builder & $27(8)$ & $6(3)$ \\
Driver & $19(6)$ & $22(10)$ \\
Fitter and turner & $19(6)$ & $4(2)$ \\
Operator & $18(5)$ & $17(8)$ \\
Painter & $16(5)$ & $0(0)$ \\
Supervisor & $14(4)$ & $8(4)$ \\
Welder & $12(3)$ & $2(1)$ \\
Maintenance & $10(3)$ & $0(0)$ \\
Manager & $9(3)$ & $17(8)$ \\
Mechanic & $6(2)$ & $5(2)$ \\
Quality control & $1(0.3)$ & $12(5)$ \\
Other & $118(35)$ & $68(31)$
\end{tabular}

*Participants generally had multiple jobs, and would be included across several of the jobs in the table.
Table 3 Employment history and occupational exposures among cases and controls

\begin{tabular}{lccc}
\hline & $\begin{array}{l}\text { Cases } \\
(\mathbf{n = 1 1 0})\end{array}$ & $\begin{array}{l}\text { Controls } \\
(\mathbf{n = 1 0 2})\end{array}$ & p Value \\
\hline Currently employed (n (\%)) & $13(12)$ & $12(12)$ & 0.97 \\
Currently unemployed (n (\%)) & $95(86)$ & $80(78)$ & 0.98 \\
Currently unemployed due to ill-health (n (\%)) & $59(54)$ & $18(17)$ & $<0.001$ \\
Self-reported exposure measures & & & \\
$\quad$ Dust exposure (n (\%)) & $79(72)$ & $28(28)$ & $<0.001$ \\
CGF exposure (n (\%)) & $82(74)$ & $26(25)$ & $<0.001$ \\
Either dust or CGF exposure (n (\%)) & $84(77)$ & $24(23)$ & $<0.001$ \\
Dust and CGF (n (\%)) & $61(55)$ & $18(17)$ & $<0.001$ \\
Total dust years (mean (SD)) & $15.7(14.7)$ & $4.7(9.2)$ & $<0.001$ \\
$\quad$ Total CGF years (mean (SD)) & $14.0(14.1)$ & $3.5(8.9)$ & $<0.001$ \\
JEM cumulative exposure years & & & \\
$\quad$ Biological dusts (mean (SD)) & $19.8(29.2)$ & $11.5(20.0)$ & 0.01 \\
Mineral dusts (mean (SD)) & $22.4(36.1)$ & $16.1(32.1)$ & 0.14 \\
CGF (mean (SD)) & $42.7(44.9)$ & $35.4(44.9)$ & 0.06 \\
\hline
\end{tabular}

CGF, chemicals, gases or fumes; JEM, Job Exposure Matrix.

higher among cases than controls (table 3). JEM cumulative exposure-years for biological dust exposure were significantly different between cases and controls, and marginally so for CGF exposure.

Logistic regression models, adjusting for smoking, TB, age and sex, strongly supported exposure-related association with COPD. The adjusted ORs all suggested an increased risk for COPD $(O R>1)$. This was more evident and consistent with the self-reported exposure variables. For the JEM variables, this was statistically significant only for the biological dust high exposure category and CGF low exposure category. A trend in ORs was observed from low to high categories for the self-reported exposures and for the JEM biological dust exposures (table 4).

Smoking history showed a strong association with COPD. The adjusted ORs for ever smokers was 5.0 (95\% CI 1.9 to 12.9), 5.5 (95\% CI 2.1 to 14.1 ) and 5.3 (95\% CI 2.1 to 13.8) from the models with biological dusts, mineral dusts and CGF variables, respectively (not shown in tables).

The strongest association with COPD as evident from our models was for TB. Depending on the model, ORs for TB ranged from 7.7 to 8.1 adjusted for age, gender, smoking status and exposure.

The PAR\% for COPD was $25 \%$ for self-reported high exposure to dusts and CGF, but much lower $(2.3-14.6 \%)$ when the JEM variables were used.

\section{DISCUSSION}

This case-control study is among the few reported hospitalbased studies showing an association between occupational exposures and COPD. The findings in our study are particularly significant given the high prevalence of $\mathrm{TB}$ in the population from which our participants were drawn. The presence of the exposure-COPD relationship after adjusting for both smoking and $\mathrm{TB}$ confirms the association of $\mathrm{COPD}$ with dust exposure in this sample.

The almost twofold increased ORs for high cumulative exposure to biological dust, adjusted for smoking and past history of $T B$, is generally in keeping with the findings reported in other studies, particularly among North American and European populations. ${ }^{22-24}$ The latter studies reported ORs from 1.3 to 3.1 , compared with our study, ranging from 1.1 to 2.2 depending on the exposure type. 
Table 4 Adjusted ORs for chronic obstructive pulmonary disease from logistic regression models*

\begin{tabular}{|c|c|c|c|c|}
\hline & $\begin{array}{l}\text { Cases } \\
(\mathbf{n}(\%))\end{array}$ & $\begin{array}{l}\text { Controls } \\
\text { (n (\%)) }\end{array}$ & $\begin{array}{l}\text { ORs } \\
\text { (95\% CI) }\end{array}$ & PAR $\%$ \\
\hline \multicolumn{5}{|l|}{ Self-reported exposure } \\
\hline \multicolumn{5}{|l|}{ Dusts } \\
\hline Unexposed & $49(45)$ & $76(74)$ & 1 & \\
\hline Low exposure-years & $27(25)$ & $13(13)$ & $4.6(1.9$ to 10.8$)$ & 19.6 \\
\hline High exposure-years & $34(31)$ & $14(14)$ & $5.9(2.6$ to 13.2$)$ & 25.7 \\
\hline \multicolumn{5}{|l|}{ Chemicals, gases and fumes } \\
\hline Unexposed & $41(37)$ & $72(70)$ & 1 & \\
\hline Low exposure-years & $32(29)$ & $15(15)$ & $2.9(1.3$ to 6.3$)$ & 18.9 \\
\hline High exposure-years & $37(34)$ & $16(15)$ & 3.6 (1.6 to 7.9$)$ & 25.6 \\
\hline \multicolumn{5}{|c|}{ Job exposure matrix exposure measures } \\
\hline \multicolumn{5}{|c|}{ Biological dusts } \\
\hline Unexposed & $39(35)$ & $50(49)$ & 1 & \\
\hline Low cumulative exposure & $27(25)$ & $25(24)$ & $1.3(0.6$ to 2.9$)$ & 5.5 \\
\hline High cumulative exposure & $44(40)$ & $27(26)$ & 2.1 (1.1 to 4.2$)$ & 13.6 \\
\hline \multicolumn{5}{|l|}{ Mineral dusts } \\
\hline Unexposed & $46(42)$ & $51(50)$ & 1 & \\
\hline Low cumulative exposure & $27(25)$ & $25(24)$ & $1.3(0.6$ to 2.7$)$ & 5.5 \\
\hline High cumulative exposure & $37(34)$ & $26(25)$ & $1.1(0.6$ to 2.4$)$ & 2.3 \\
\hline \multicolumn{5}{|l|}{ Chemicals, gases and fumes } \\
\hline Unexposed & $21(19)$ & $36(35)$ & 1 & \\
\hline Low cumulative exposure & $44(40)$ & $33(32)$ & $2.2(1.1$ to 4.7$)$ & 17.5 \\
\hline High cumulative exposure & $45(41)$ & $34(33)$ & $1.8(0.8$ to 3.9$)$ & 14.6 \\
\hline
\end{tabular}

*Models adjusted for age, sex, current smoker, ex-smoker, history of tuberculosis

There was limited evidence of correlation between the various exposure measures, but when regression models included multiple exposure variables, the effect estimates became smaller, and CIs widened.

Although the estimates reported in our study are generally in keeping with those reported from other international studies, our findings are particularly striking because of its control for $\mathrm{TB}-\mathrm{a}$ disease of high prevalence within the population from which our sample was drawn. Studies have repeatedly reported the elevated risk for the development of COPD in those with a past history of $\mathrm{TB} .{ }^{13-15} \mathrm{~A}$ recent Chinese study of airflow obstruction and TB reported an increased age-, smoking- and occupational dust-adjusted risk for airflow obstruction among those with prior TB (OR 1.37; 95\% CI 1.1 to 1.7). Occupational dust exposure in the longest job held did not change the risk for prior TB. ${ }^{15}$ The rate of TB among South Africans is among the highest in the world, with an incident rate of 948/100 000 population. ${ }^{25}$ Thus, smoking and TB are considered to be the leading causes of COPD in South Africa. ${ }^{26} \mathrm{~TB}$ and non-specific occupational exposure have also been shown to be independent risk factors for chronic bronchitis ${ }^{26}$ and chronic wheeze ${ }^{27}$ in the South African population. Our study, in adjusting for these factors, provides additional evidence for the role of dusts, chemicals, gases, vapours and fumes in the development of COPD.

This study has a number of strengths that provide confidence in the findings. The case-control design, with cases being defined through a pulmonologist assessment, selected from specialist respiratory clinics, using clinical and lung function parameters according to the GOLD criteria, limits possible disease misclassification. The selection of non-respiratory specialist clinic-based controls, under the care of internal medicine specialists, who clinically excluded diagnoses of chronic respiratory disease, also limits disease misclassification Our ability to obtain detailed lifetime occupational histories permitted the determination of relatively precise exposure metrics, and together with the use of a COPD-validated JEM reduced possible bias in our exposure assessment. In recruiting COPD cases from specialist pulmonology clinics, this study probably has an advantage over population-based studies which are dependent on patient-based responses for the classification of outcome. ${ }^{22} 28$

There were several limitations to our study. Our decision to select patients presenting to specialist respiratory clinics in the public sector hospitals created a strong selection bias. First, because of the access to high standards of private medical care available for those with health insurance in South Africa, patients presenting to the public sector come from a narrow and low socio-economic band. The socio-economic variables collected during the study were employment status, home ownership and energy source, and these did not differ between cases and controls. We did not adjust for use of biomass fuels in this study, a known factor in the development of COPD in the developing world. Controls were selected from specific chronic diseases clinics, and therefore were not representative of the general population. Generally patients with moderate to severe disease (69\% of cases were in GOLD III and IV stages), refractory to medical management from primary care medical practitioners, are referred to these specialist centres. Thus our findings are not generalisable to the broader population with COPD, but serve to affirm the association of occupational dust exposure with COPD. By definition, all potential controls with COPD and chronic bronchitis, asthma or emphysema were excluded, and this could have reduced the number of controls with TB inasmuch as $\mathrm{TB}$ is related to these chronic diseases. However, from all those eligible to become controls (ie, patients from nonrespiratory chronic diseases clinics meeting the age and gender criteria) no more than $5 \%$ were screened out on the basis of having these diagnoses. Thus the under-representation of TB among the controls is not likely to have been substantial.

Additionally, our study may not be comparable with the broader blue collar working population in South Africa, because of the minimal mining exposure among our sample. The province, and particularly the cities, from which this sample was drawn are largely outside the key mining centres of South Africa. This lack of mining exposure is important because of our interest in TB. TB is on the causal pathway for COPD among those exposed to silica dust. While the absence of mining in our sample reduces this exposure, its presence in other industries such as sandblasting, welding and building could be a contributory factor. In our sample, $<10 \%$ reported working in these industries, and no participant admitted to having had silica exposure.

Our small sample size, together with the small number of never-smokers particularly among the cases, is an important limitation. We were not able to investigate the risk by smoking status satisfactorily.

Another limitation was the lack of verification of the occupational history reported by the patients. Because most patients were recalling histories that dated back some $20-30$ years ago, it is likely that this may have been reported erroneously. It is, however, documented that workers' recollection of dust exposure correlated well with actual dust sampling in the workplace. ${ }^{29}{ }^{30} \mathrm{~A}$ recall bias may have existed if such errors were more likely to have been present in the reporting by cases as compared with controls. It is very possible that those with COPD were more likely to recall and report working in environments with respiratory irritants. This is supported by effect estimates from models, with the self-reporting of exposure being much higher than estimates using JEM exposure measures. It is 
likely that the use of this JEM, previously used in populationbased COPD studies, adjusted for the recall bias that may have been present. ${ }^{8} 20$

There are likely to be disadvantages to the ALOHA JEM, but it is not likely to be substantially different from any other JEM, or developing one specific for this population. ${ }^{31}$ Expert- and taskbased information does not necessarily lead to better exposure asssessment. $^{32}$ Expert-based assessment depending on selfreports or self-reported exposure has, however, the additional problem of differential misclassification because of responder bias. A JEM is not likely to suffer from this.

In conclusion, our study not only lends support to the growing body of literature associating workplace exposures with COPD, but also suggests that among a population with a high prevalence of TB and cigarette smoking, occupational exposures remain an important factor. Controlling workplace exposures, together with antismoking and $\mathrm{TB}$ prevention programmes, is important if the increasing global prevalence of COPD is to be addressed.

Acknowledgements The authors wish to thank the medical and nursing staff at the three participating clinics, the public sector hospitals at which these clinics are based, as well as the participating patients. We are particularly appreciative of the assistance with the ALOHA JEM provided by Hans Kromhout and his colleagues at the Institute for Risk Assessment at Utrecht University.

Funding The study was supported through research funds of the University of KwaZulu-Natal.

\section{Competing interests None.}

Ethics approval This study was conducted with the approval of the University of KwaZulu-Natal Biomedical Research Ethics Committee.

Provenance and peer review Not commissioned; externally peer reviewed.

\section{REFERENCES}

1. Lopez AD, Mathers CD, Ezzati M, et al. Global Burden of Disease and Risk Factors. Washington, DC: The World Bank, 2006.

2. Balmes J, Becklake M, Blanc P, et al. American Thoracic Society Statement: Occupational contribution to the burden of airway disease. Am J Respir Crit Care Med 2003;167:787-97.

3. Eisner MD, Anthonisen N, Coultas D, et al. An official American Thoracic Society public policy statement: Novel risk factors and the global burden of chronic obstructive pulmonary disease. Am J Respir Crit Care Med 2010;182:693-718.

4. Harber $\mathbf{P}$, Tashkin DP, Simmons M, et al. Effect of occupational exposures on decline of lung function in early chronic obstructive pulmonary disease. Am J Respir Crit Care Med 2007;176:994-1000.

5. Becklake MR. Occupational exposures: evidence for a causal association with chronic obstructive pulmonary disease. Am Rev Respir Dis 1989;140:S85-91

6. Hnizdo E, Sullivan PA, Bang KM, et al. Association between chronic obstructive pulmonary disease and employment by industry and occupation in the US population: a study of data from the Third National Health and Nutrition Examination Survey. Am J Epidemiol 2002:156:738-46.

7. Blanc PD, Iribarren C, Trupin L, et al. Occupational exposures and the risk of COPD: dusty trades revisited. Thorax 2009;64:6-12.

8. Sunyer J, Kogevinas M, Kromhout $\mathrm{H}$, et al. Pulmonary ventilatory defects and occupational exposures in a population-based study in Spain. Spanish Group of the
European Community Respiratory Health Survey. Am J Respir Crit Care Med 1998; 157:512-17.

9. Christiani DC, Wang XR, Pan LD, et al. Longitudinal changes in pulmonary function and respiratory symptoms in cotton textile workers. A 15-yr followup study. Am J Respir Crit Care Med 2001;163:847-53.

10. Hart JE, Laden F, Eisen EA, et al. Chronic obstructive pulmonary disease mortality in railroad workers. Occup Environ Med 2009;66:221-6.

11. Girdler-Brown BV, White NW, Ehrlich Rl, et al. The burden of silicosis, pulmonary tuberculosis and COPD among former Basotho goldminers. Am J Ind Med 2008; 51:640-7.

12. Eduard W, Pearce N, Douwes J. Chronic bronchitis, COPD, and lung function in farmers: the role of biological agents. Chest 2009;136:716-25.

13. Van Zyl Smit RN, Pai M, Yew WW, et al. Global lung health: the colliding epidemics of tuberculosis, tobacco smoking, HIV and COPD. Eur Respir J 2010;35:27-33.

14. Chan-Yeung $\mathbf{M}, \mathrm{Ho}$ AS, Cheung AH, et al. Determinants of chronic obstructive pulmonary disease in Chinese patients in Hong Kong. Int $J$ Tuberc Lung Dis 2007:11:502-7.

15. Lam KB, Jiang CQ, Jordan RE, et al. Prior TB, smoking, and airflow obstruction: a cross-sectional analysis of the Guangzhou Biobank Cohort Study. Chest 2010:137:593-600.

16. Pauwels RA, Buist AS, Calverley PM, et al. Global strategy for the diagnosis, management, and prevention of chronic obstructive pulmonary disease. NHLBI/WHO Global Initiative for Chronic Obstructive Lung Disease (GOLD) Workshop summary. Am J Respir Crit Care Med 2001;163:1256-76.

17. Naidoo RN, Robins TG, Seixas N, et al. Respirable coal dust exposure and respiratory symptoms in South African coal miners: a comparison of current and ex-miners. J Occup Environ Med 2006;48:581-90.

18. European Community Respiratory Health Survey Steering Group. ECRHS II Main Questionnaire. 2007. http://www.ecrhs.org (accessed 24 Nov 2010).

19. International Labour Office. International Standard Classification of Occupations: ISCO-88. Geneva: International Labour Organization, 1990.

20. Matheson MC, Benke G, Raven J, et al. Biological dust exposure in the workplace is a risk factor for chronic obstructive pulmonary disease. Thorax 2005;60:645-51.

21. Weinmann S, Vollmer WM, Breen V, et al. COPD and occupational exposures: a case-control study. J Occup Environ Med 2008;50:561-9.

22. Trupin L, Earnest G, San Pedro M, et al. The occupational burden of chronic obstructive pulmonary disease. Eur Respir J 2003;22:462-9.

23. Zock JP, Sunyer J, Kogevinas M, et al. Occupation, chronic bronchitis, and lung function in young adults. An international study. Am J Respir Crit Care Med 2001;163:1572-7.

24. Mastrangelo G, Tartari M, Fedeli U, et al. Ascertaining the risk of chronic obstructive pulmonary disease in relation to occupation using a case-control design Occup Med (Lond) 2003;53:165-72.

25. World Health Organization. Global Tuberculosis Control: Epidemiology, Strategy, Financing. WHO/HTM/TB/2009.411. Geneva, Switzerland: WHO, 2009.

26. Ehrlich RI, White N, Norman R, et al. Predictors of chronic bronchitis in South African adults. Int J Tuberc Lung Dis 2004;8:369-76.

27. Ehrlich RI, White N, Norman R, et al. Wheeze, asthma diagnosis and medication use: a national adult survey in a developing country. Thorax 2005;60:895-901.

28. Blanc PD, Eisner MD, Trupin $\mathrm{L}$, et al. The association between occupational factors and adverse health outcomes in chronic obstructive pulmonary disease. Occup Environ Med 2004;61:661-7.

29. Lander L, Sorock G, Stentz TL, et al. Validation of self-reported occupational exposures in meatpacking workers. Am J Ind Med 2009;52:707-15.

30. Delclos GL, Gimeno D, Arif AA, et al. Occupational exposures and asthma in healthcare workers: comparison of self-reports with a workplace-specific job exposure matrix. Am J Epidemiol 2009;169:581-7.

31. Le Moual N, Bakke P, Orlowski E, et al. Performance of population specific job exposure matrices (JEMs): European collaborative analyses on occupational risk factors for chronic obstructive pulmonary disease with job exposure matrices (ECOJEM). Occup Environ Med 2000:57:126-32.

32. Peters S, Vermeulen R, Cassidy A, et al; INCO Group. Comparison of exposure assessment methods for occupational carcinogens in a multi-centre lung cancer case-control study. Occup Environ Med 2011;68:148-53. 